\title{
Experimental Study of Effect of Parameter variations on output parameters for Electrochemical Machining of SS AISI 202
}

\author{
S. S. Uttarwar* and I. K. Chopde** \\ "Department of Mechanical Engineering, Priyadarshini College of Engineering, Nagpur, \\ Maharashtra, India \\ ** Department of Mechanical Engineering, Visvesvaraya National Institute of Technology, Nagpur \\ Maharashtra, India
}

\begin{abstract}
This paper presents results of the Electrochemical Machining (ECM) process, which was used to machine the SS AISI 202. Specifically, the Material Removal Rate (MRR) and Surface Roughness (SR) as a function of ECM were determined. The experimental work was based on the Taguchi approach of experimentation and table $L_{32}$ was used. Furthermore, a theoretical and computational model is presented to illustrate the influence parameter variations in results. In addition to this the influence of independent parameters such as time of electrolysis, voltage, current, concentration of electrolyte, feed rate and pressure upon the amount of material removed and SR. The results indicated that MRR was remarkably affected by variation in current and Surface Roughness decreased with increase in current. Hence, it was apparent that irregular MRR was more likely to occur at high currents. The results showed that MRR increased with increasing electrical voltage, molar concentration of electrolyte, time of electrolysis and feed rate. However, the time of electrolysis was the most influential parameter on the produced surface finish.
\end{abstract}

Keywords: Electrochemical machining; Material removal rate; Time; Feed rate; electrolyte concentration.

\section{Introduction}

Earlier the machining of complex shaped designs was difficult, however, with the advent of the new machining processes that incorporate in it chemical, electrical and mechanical processes, manufacturing process has redefined itself. ${ }^{[3]}$ Electrochemical machining (ECM), a nontraditional process for machining ${ }^{[1,2]}$ has been recognized now a days for performing numerous machining operations. ${ }^{[4]}$ The new and improved machining processes are often referred to as unconventional machining processes. For e.g. ECM removes material without heat. Almost all types of metals can be machined by this process. In today's high precision and time sensitive scenario, ECM has wide scope for applications. ${ }^{[5]}$ More specifically, ECM is a process based on the controlled anodic dissolution of the work piece anode, ${ }^{[6]}$ with the tool as the cathode, in an electrolytic solution. ${ }^{[11]}$ The electrolyte flows between the electrodes and carries away the dissolved metal.

Since the first introduction of ECM in 1929 by Gusseff, its industrial applications have been extended to electrochemical drilling, electrochemical deburring, electrochemical grinding and electrochemical polishing. ${ }^{[13]}$ More specifically, ECM was found more advantageous for high-strength alloys. Today, ECM has been increasingly recognized for its potential for machining ${ }^{[7]}$ while the precision of the machined profile is a concern of its application. ${ }^{[9,10]}$ During the ECM process, electrical current passes through an electrolyte solution between a cathode tool and an anode work piece. The work piece is eroded in accordance with Faraday's law of electrolysis. ${ }^{[12]}$ ECM processes find wide applicability in areas such as aerospace and electronic industries for shaping and finishing operations of a variety of parts that are a few microns in diameter. ${ }^{[13]}$ Furthermore, it has been reported that the accuracy of machining can be improved by the use of pulsed electrical current and controlling various process parameters. Amongst the often considered parameters are electrolyte concentration, voltage, current and inter electrode gap. ${ }^{[14]}$ Though there is a possibility of improving the precision of work, the dependency of accuracy on numerous parameters demand that a thorough investigation should be carried out to ascertain the causality to different parameters. In the backdrop of above information, this study was carried out to assess the best conditions (with respect to different process parameters) for improving the accuracy of ECM process. In this paper the authors propose an analytical model of electrochemical erosion to predict the finishing machined work piece. The study envisaged an empirical data obtained from the experiments carried out to assess effect of operating parameter variations on material removal rate (MRR) and surface roughness (SR) for Stainless steel (AISI 202).

\section{ECM setup}

Fig 1and 2 shows the schematic set up of ECM in which two electrodes were placed at a distance of about 0.1 to $1 \mathrm{~mm}$ and immersed in an electrolyte, which was a solution of sodium chloride. ${ }^{[15]}$ When an 
electrical potential (of about $20 \mathrm{~V}$ ) is applied between the electrodes, the ions existing in the electrolyte migrate toward the electrodes ${ }^{[15]}$.

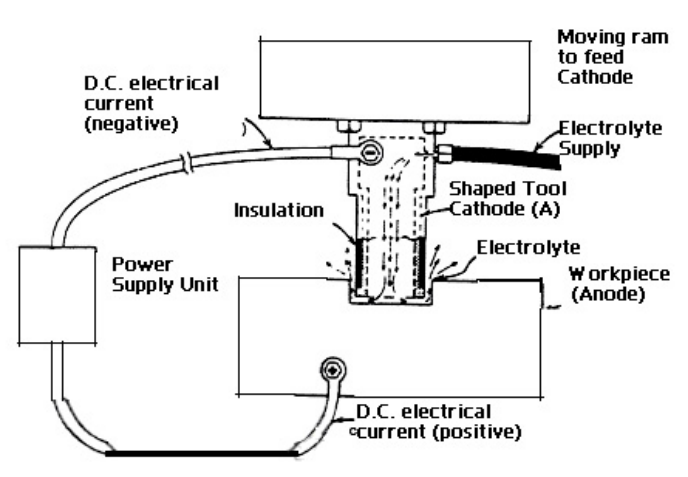

Fig 1. ECM Setup

\subsection{Material removal rate:}

\section{Output Parameters of ECM}

The MRR primarily depends on the feed rates. The feed rate determines the amount of current that can pass through the work and the tool. As the tool approaches the work piece the length of the conductive current path decreases and the magnitude of current increases. This continues until the current is just sufficient to remove the metal at a rate corresponding to the rate of tool advance. Thereafter a stable cut is made available with a fixed spacing between the work and the tool, which is termed as the equilibrium-machining gap. If the tool feed rate is reduced, the tool advance will momentarily lag behind, increasing the gap and thus resulting in a reduction of current. This happens until a stable gap is once again established. Thus, the feed rate is an important parameter, which was given due consideration in the experiment.

\subsection{Surface Finish}

ECM under certain conditions can produce surface finishes of the order of $0.4 \mathrm{~mm}$. This can be obtained by the frontal cut or the rotation of the tool or the work. Hence care was taken to control the important variables affecting the surface finish are feed rate, voltage, electrolyte composition, pressure, current \& flow.

\section{Process Parameters of ECM}

The operating parameters which are within the control of the operator and which influence ECM process capabilities are as follows: ${ }^{[14],[15]}$

\subsection{Current}

Current plays a vital role in ECM. The MRR is directly proportions to the current (i.e. MRR increases with increase in current). However, this increase can be observed up to a certain limit and exceeding current beyond this level negatively affects accuracy and finishing of work piece. Hence, care was taken to apply current in the desired way.

\subsection{Feed Rate}

Feed rate governs the gap between the tool (cathode) and the work piece (anode) it is important for metal removal in ECM. ${ }^{[6]}$ It plays a major role for accuracy in shape generation and hence was constantly monitored.

\subsection{Electrolyte and its concentration}

ECM electrolyte is generally classified into two categories, passivity electrolyte containing oxidizing anions e.g. sodium nitrate and sodium chlorate, etc. and non-passivity electrolyte containing relatively aggressive anions such as sodium chloride. Passivity electrolytes are known to give better machining precision. This is due to their ability to form oxide films and evolve oxygen in the stray current region. From review of past research, in most of the investigations researchers recommended $\mathrm{NaClO}_{3}, \mathrm{NaNO}_{3}$, and $\mathrm{NaCl}$ solution with different concentration for $\mathrm{ECM}$ and hence, $\mathrm{NaCl}$ was used as an electrolyte in this experimentation with concentration of $125 \mathrm{gm} / \mathrm{lit}$ and $150 \mathrm{gm} / \mathrm{lt}$. 


\subsection{Voltage}

The nature of applied power supply is of two types, DC (full wave rectified) and pulse DC. A full wave rectified DC supplies continuous voltage and a pulse generator is used to supply pulses of voltage with specific on-time and off-time. The MRR is proportional to the applied voltage. But, the experimental values were found to be varying non-linearly with voltage. This is mainly because of less dissolution efficiency in the low voltage zone as compared to the high voltage zone. ${ }^{[12]}$ However continuous voltage supply is used for this experimentation work.

\section{Experimental setup}

Fig 3 shows actual photograph of the experimental set up of ECM on which the experimentation process was carried out.

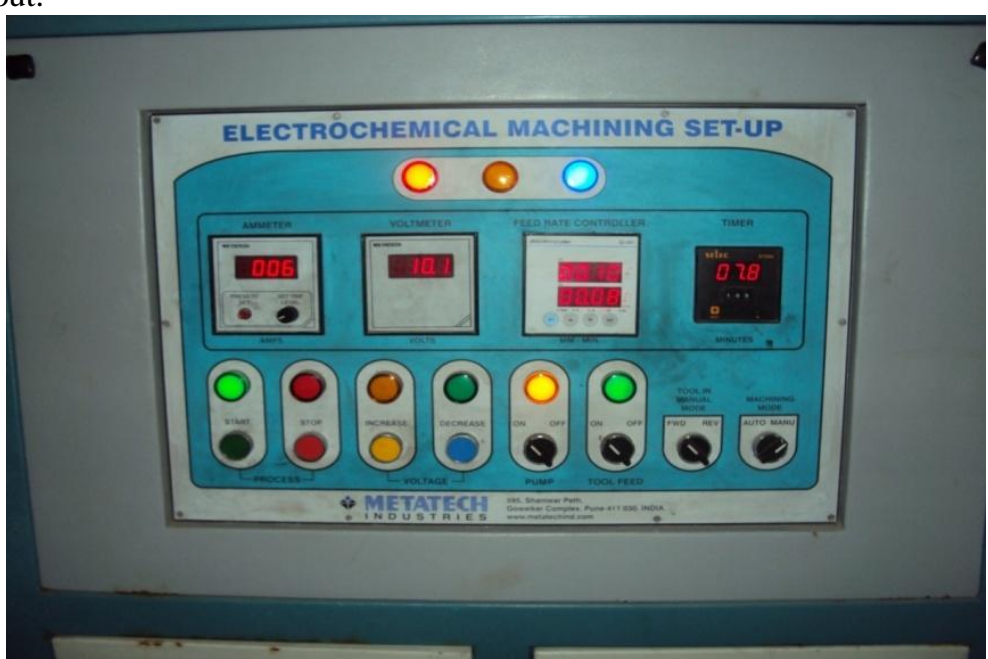

Fig 3. Experimental set up of ECM process

\subsection{Tool and Work piece Material}

The tool used in this study was made up of copper while the work-piece used is this study was made up of Stainless Steel SS 202. This work piece was selected for this study as it has wide applications in various fields. The chemical composition of the used work piece i.e. SS 202 was as follows

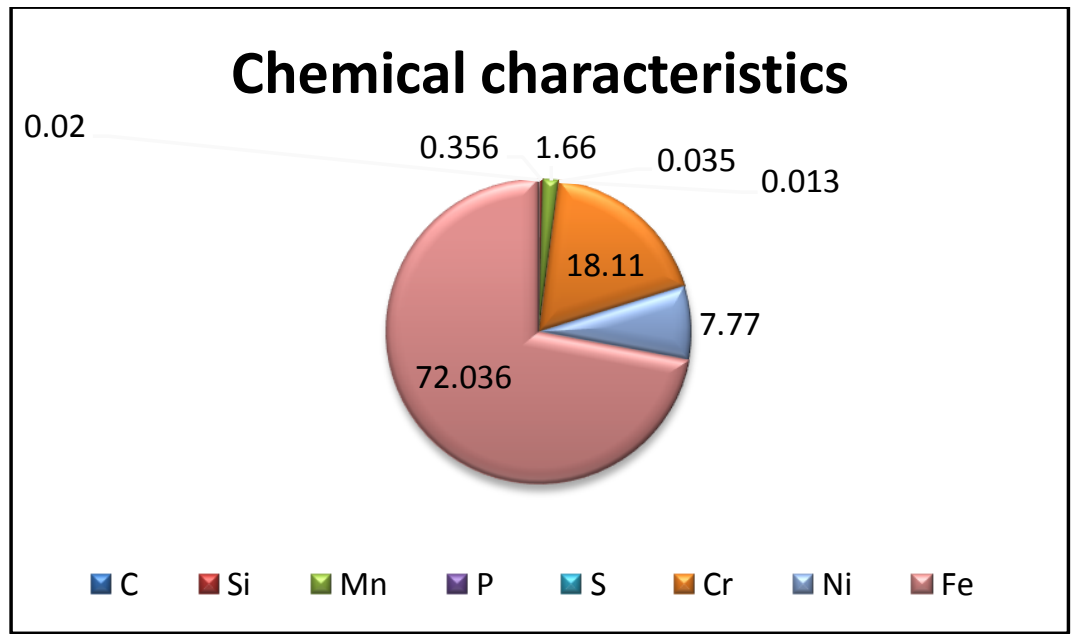

Fig 4. Chemical characteristics of work piece SS 202

\section{Experimentation Work}

An Orthogonal Array $\mathrm{L}_{32}\left(2^{1} * 4^{5}\right)$ of Taguchi method was used for conducting the experimentation work. The results of dependent parameters (MRR and SR) with respect to all levels of independent parameters are shown in a following table. 
Table 2 Values of Dependent and Independent Parameters (Orthogonal array L 32)

\begin{tabular}{|c|c|c|c|c|c|c|c|c|}
\hline \multirow{3}{*}{$\begin{array}{l}\text { Run } \\
\text { No. }\end{array}$} & \multicolumn{6}{|c|}{ Independent parameters } & \multicolumn{2}{|c|}{ Dependent parameters } \\
\hline & $\begin{array}{c}\text { Electrolyt } \\
\mathrm{e} \\
\text { Conc. } \\
\text { (gms/Ltr) }\end{array}$ & $\begin{array}{c}\text { Voltag } \\
\text { e } \\
(\mathrm{V})\end{array}$ & $\begin{array}{c}\text { Curren } \\
t \\
\text { (Amp) }\end{array}$ & $\begin{array}{c}\text { Feed } \\
(\mathrm{MM} / \mathrm{min} \\
)\end{array}$ & $\begin{array}{l}\text { Electrolyt } \\
\text { e Flow } \\
\text { (Ltrs/min) }\end{array}$ & $\begin{array}{c}\text { Pressure } \\
\left(\mathrm{Kg} / \mathrm{Cm}^{2}\right. \\
)\end{array}$ & $\begin{array}{c}\text { MRR } \\
(\mathrm{mg} / \mathrm{min})\end{array}$ & $\begin{array}{c}\text { SR } \\
(\mu \mathrm{m})\end{array}$ \\
\hline & $\mathrm{E}$ & $\mathrm{B}$ & A & 0.1 & $\mathrm{C}$ & $\mathrm{F}$ & $G$ & $H$ \\
\hline 1 & 125 & 10 & 100 & 0.2 & 4 & 3.4 & 4.173 & 3.490 \\
\hline 2 & 125 & 10 & 125 & 0.3 & 5 & 3.6 & 3.676 & 2.584 \\
\hline 3 & 125 & 10 & 150 & 0.4 & 6 & 3.7 & 4.335 & 2.246 \\
\hline 4 & 125 & 10 & 175 & 0.1 & 7 & 3.8 & 3.914 & 3.306 \\
\hline 5 & 125 & 14 & 100 & 0.2 & 5 & 3.6 & 3.794 & 3.389 \\
\hline 6 & 125 & 14 & 125 & 0.3 & 4 & 3.4 & 4.334 & 3.140 \\
\hline 7 & 125 & 14 & 150 & 0.4 & 7 & 3.8 & 3.719 & 2.463 \\
\hline 8 & 125 & 14 & 175 & 0.2 & 6 & 3.7 & 3.356 & 2.323 \\
\hline 9 & 125 & 18 & 100 & 0.1 & 6 & 3.8 & 4.434 & 4.286 \\
\hline 10 & 125 & 18 & 125 & 0.4 & 7 & 3.7 & 4.835 & 2.166 \\
\hline 11 & 125 & 18 & 150 & 0.3 & 4 & 3.6 & 3.413 & 2.528 \\
\hline 12 & 125 & 18 & 175 & 0.2 & 5 & 3.4 & 5.172 & 3.521 \\
\hline 13 & 125 & 22 & 100 & 0.1 & 7 & 3.7 & 4.224 & 3.202 \\
\hline 14 & 125 & 22 & 125 & 0.4 & 6 & 3.8 & 4.463 & 3.455 \\
\hline 15 & 125 & 22 & 150 & 0.3 & 5 & 3.4 & 4.448 & 2.953 \\
\hline 16 & 125 & 22 & 175 & 0.4 & 4 & 3.6 & 4.583 & 2.433 \\
\hline 17 & 150 & 10 & 100 & 0.3 & 4 & 3.8 & 3.879 & 2.883 \\
\hline 18 & 150 & 10 & 125 & 0.2 & 5 & 3.7 & 4.808 & 2.453 \\
\hline 19 & 150 & 10 & 150 & 0.1 & 6 & 3.6 & 3.757 & 2.449 \\
\hline 20 & 150 & 10 & 175 & 0.4 & 7 & 3.4 & 4.945 & 3.541 \\
\hline 21 & 150 & 14 & 100 & 0.3 & 5 & 3.7 & 4.486 & 2.462 \\
\hline 22 & 150 & 14 & 125 & 0.2 & 4 & 3,8 & 3.310 & 2.488 \\
\hline 23 & 150 & 14 & 150 & 0.1 & 7 & 3.4 & 5.309 & 2.483 \\
\hline 24 & 150 & 14 & 175 & 0.3 & 6 & 3.6 & 4.413 & 2.364 \\
\hline 25 & 150 & 18 & 100 & 0.4 & 6 & 3.4 & 4.208 & 2.503 \\
\hline 26 & 150 & 18 & 125 & 0.1 & 7 & 3.6 & 5.097 & 2.134 \\
\hline 27 & 150 & 18 & 150 & 0.2 & 4 & 3.7 & 4.296 & 2.605 \\
\hline 28 & 150 & 18 & 175 & 0.3 & 5 & 3.8 & 4.400 & 4.669 \\
\hline 29 & 150 & 22 & 100 & 0.4 & 7 & 3.6 & 4.443 & 2.774 \\
\hline 30 & 150 & 22 & 125 & 0.1 & 6 & 3.4 & 3.323 & 2.658 \\
\hline 31 & 150 & 22 & 150 & 0.2 & 5 & 3.8 & 3.173 & 2.393 \\
\hline 32 & 150 & 22 & 175 & 0.3 & 4 & 3.7 & 4.311 & 4.576 \\
\hline$\sum$ & 4400 & 512 & 4400 & 0.4 & 176 & 112.2 & 135.02891 & 92.91721 \\
\hline
\end{tabular}

\section{Mathematical Model for MRR and SR}

Using Regression Analysis Mathematical models were developed for MRR and SR with their indices. The six decision variables concerned for this model were Current, Voltage, feed rate, Pressure, Electrolyte concentration and flow of electrolyte.

\subsection{Objectives}

The various objectives under consideration for the formulation of model were

a) Maximization of MRR and

b) Improving SR (surface finish) and dimensional accuracy

\subsection{Derived mathematical Models}

Equation 1 and 2 are the mathematical models derived for calculation of MRR and SR.

MRR $=$ Constant $\times A^{a} \times B^{b} \times C^{c} \times D^{d} \times E^{e} \times F^{f}$

Where a,b,c,d,e,f are the indices for current, voltage, electrolyte flow, feed rate, Electrolyte concentration and pressure. The formulated models are as follows

MRR $=3.14695 \mathrm{~A}^{0.002050} * \mathrm{~B}^{-0.01061875} * \mathrm{C}^{0.001225} * \mathrm{D}^{0.10975} * \mathrm{E}^{-0.00345} * \mathrm{~F}^{-0.0104625}$-.-.-- Eqn 1

$\mathbf{S R}=2.2425000 \mathrm{~A}^{0.0024500} * \mathrm{~B}^{-0.0196875} * \mathrm{C}^{0.0212500} * \mathrm{D}^{0.0375000} * \mathrm{E}^{-0.0022500} * \mathrm{~F}^{0.0093750--}$ Eqn 2 
From the Eqns. 1 and 2, it was evident that the MRR was positively influenced by the independent variables such as current, electrolyte flow and feed rate whereas negatively influenced by voltage, electrolyte concentration and pressure. Moreover, the SR was observed to be positively influenced by current, electrolyte flow, feed rate, and electrolyte concentration whereas it (SR) is negatively influenced by voltage and electrolyte concentration.

\section{Comparison of Practical v/s Theoretical values of MRR}

A sample set of Comparison of Actual value of MRR calculated by formula and corresponding values derived by mathematical model is shown in Table 3 along with the calculated percentage error.

Table 3: Comparative assessment of the Practical v/s Theoretical values of MRR

\begin{tabular}{|c|c|c|c|}
\hline \multirow{2}{*}{ Sr. No. } & \multicolumn{2}{|c|}{ Values of Dependent Parameter (MRR) } & $\begin{array}{c}\text { Percentage } \\
\text { Error }\end{array}$ \\
\cline { 2 - 3 } & By Mathematical Model & Actual Experimentation & 4.3123 \\
\hline 1 & 4.352950577 & 4.173 & 9.7610 \\
\hline 2 & 4.034813503 & 3.676 & -11.0844 \\
\hline
\end{tabular}

\section{Comparison of Practical v/s Theoretical values of SR}

A sample set of Comparison of Actual value of SR calculated by formula and corresponding values derived by mathematical model is shown in Table 4 with Percentage error.

Table 4: Comparative assessment of the Practical v/s Theoretical values of SR

\begin{tabular}{|c|c|c|c|}
\hline \multirow{2}{*}{ Sr. No. } & \multicolumn{2}{|c|}{ Values of Dependent Parameter (SR) } & \multirow{2}{*}{$\begin{array}{c}\text { Percentage } \\
\text { Error }\end{array}$} \\
\cline { 2 - 3 } & By Mathematical Model & Actual Experimentation & -14.6560 \\
\hline 1 & 2.81894509 & 3.306 & -5.9416 \\
\hline 2 & 3.069285646 & 3.389 & -8.2054 \\
\hline 3 & 2.971275158 & 3.140 & \multirow{2}{*}{} \\
\hline
\end{tabular}

\section{Percentage Error}

Percentage error graphs for difference in actual and theoretical values of MRR and SR are plotted with error on $\mathrm{Y}$ axis and readings on $\mathrm{X}$ axis. Fig 5 and 6 shows percentage error in actual and Experimental values of MRR and SR. it was evident from the graphs that the different test runs showed noticeable variation in the percentage error of both the dependent parameters i.e. MRR and SR.

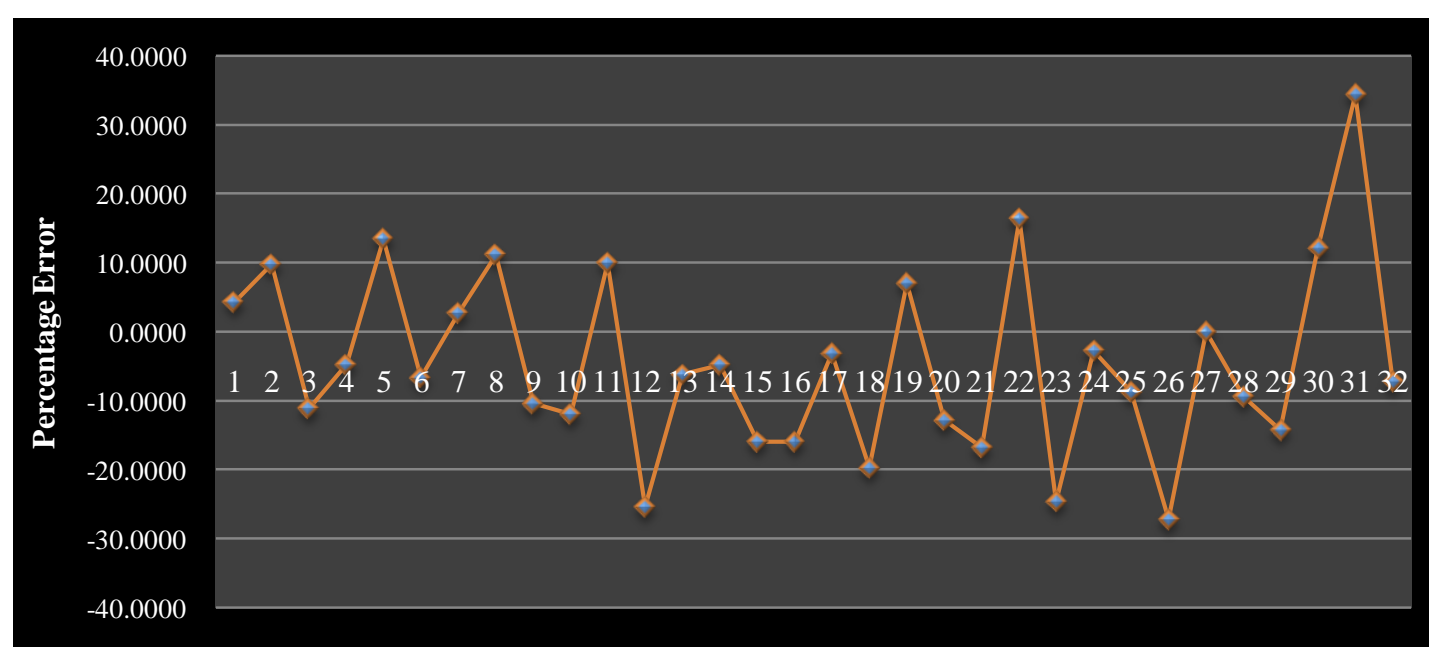

Fig 5. Percentage Error Graph for MRR 


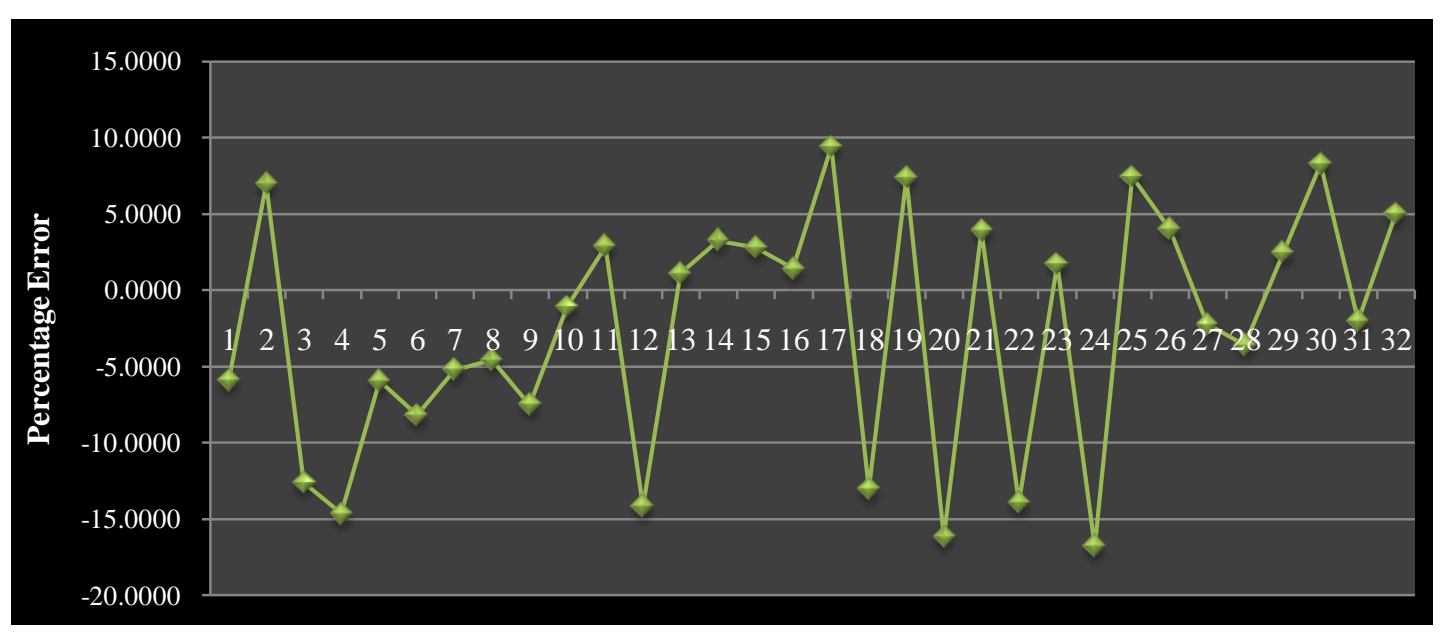

Fig 6. Percentage Error Graph for SR

\section{Results}

It was observed that MRR was considerably affected by variation in current and SR decreased with increase in current. Hence, it was apparent that irregular removal of material was more likely to occur at high currents. The $\mathrm{NaCl}$ electrolyte was responsible for the lower SR and over-cut. Furthermore, MRR increased with flow rate because there was more mobility of the ions from the metal to the solution, thereby increasing the speed of the chemical reactions. Besides, there was a need to constantly remove the sludge formed during machining, which was necessary as the sludge accumulation could have negatively affected the machining efficiency of the ECM process. Results of entire experimentation work are as under:

A) Optimum value of MRR is as follows

\begin{tabular}{|l|c|c|}
\hline & Actual & By Model \\
\hline Optimum Value of MRR & $5.390 \mathrm{mg} / \mathrm{min}$ & $4.296 \mathrm{mg} / \mathrm{min}$ \\
\hline Corresponding value of SR for this MRR & $2.483 \mu \mathrm{m}$ & $2.014 \mu \mathrm{m}$ \\
\hline
\end{tabular}

Values of various operating parameters for above said maximum value of MRR were Current 150A, Voltage 14 volts, Flow Rate 7Ltr/Min, IEG $0.2 \mathrm{~mm}$, Electrolyte concentration 150g/lit and Pressure $3.4 \mathrm{Kg} / \mathrm{cm}^{2}$. B)

Optimum value of SR is as follows
\begin{tabular}{|l|c|c|}
\hline & Actual & By Model \\
\hline Optimum Value of SR & $2.166 \mu \mathrm{m}$ & $2.06560 \mu \mathrm{m}$ \\
\hline Corresponding value of MRR for this SR & $4.834 \mathrm{mg} / \mathrm{min}$ & $4.259 \mathrm{mg} / \mathrm{min}$ \\
\hline
\end{tabular}

Values of various operating parameters for above said optimum value of SR were Current 125A, Voltage 18volt, Flow Rate 7Ltr/Min, IEG 0.1mm, Electrolyte concentration 125g/Lit and Pressure $3.7 \mathrm{~kg} / \mathrm{cm}^{2}$.

\section{Conclusion}

The different combinations of the controlling factors were considered for the experimentation and to determine their (independent parameter's) influence on MRR and SR of SS202 work piece. The experimentation was carried out by varying all parameters in combination as per orthogonal array $\mathrm{L}_{32}$. On the basis of the results obtained in this work, main conclusion can be stated as the selection of appropriate values for the different parameters of ECM process is crucial to achieve the efficiency and high quality of outcome from the process. Furthermore, similar experimental work can be continued to determine optimum process conditions for ECM process for other types of stainless steel. In addition to this the difference between the theoretical and practical values of MRR and SR are also required (for other stainless Steels) to give some thought, to reduce \% error .

\section{References}

[1] J.A. Mc Geough, Principle of Electrochemical Machining. Chapman and Hall, London, 1974.

[2] P. Asokan, R Ravikumar, R Jeyapaul, M Santhi “ Development of multi objective optimization models for Electrochemical Machining Process" Springer. Int J Adv. Munaf Technol( 2008) 39:55-63 DOI 10.1007/s00170-007-1204-8

[3] M. Hardopoulos - S. Turgeon - C. Sarra-Bournet - G. Laroche - D. Mantovani "Development of an optimized electrochemical process for subsequent coating of 316 stainless steel for stent applications" Received: 19 January 2004 / Accepted: 24 October 2005 Springer Science+Business Media, LLC 2006 
[4] K.L. Senthil Kumar, R. Sivasubramanian, K. Kalaiselvan, "Selection of Optimum Parameters in Non Conventional Machining of Metal Matrix Composite" Portugalia Electrochemica Acta 2009 27(4) 477-486.

[5] R V Rao, P J Pawar, R Shankar "Multi objective optimization of electrochemical machining process parameters using a particle swarm optimization algorithm” DOI:10.1243/09544054JEM1158 Proc. I mech E Vol 222 (2008) Part B

[6] J.A. McGeough and X. K. Chen, Machining methods: electrochemical, in "Kirk-Othmer J. I.

[7] S K Mukherjee, s Kumar, P K shrivastava, Arbind Kumar " Effect of valency on material removal rate in electrochemical machining of aluminium" Elesevier Journal of material processing Technology 202(2008) 398-401

[8] B Bhattacharyya S K Sorkhel “ Investigation for controlled electrochemical machining through response surface methodology based approach"Elesevier Journal of Processing Technology 86(1999) 200-207.

[9] Jo ao Cirilo da Silva Neto, Evaldo Malaquias da Silva, Marcio Bacci da Silva, 'Intervening variables in electrochemical machining' Journal of Materials Processing Technology 179 (2006) 92-96

[10] J.A. McGeough, Advanced Methods of Machining, Chapman and Hall, London, 1988, pp. 55-88.

[11] J. Tlusty, Manufacturing Process and Equipment, 1st ed., Prentice-Hall, USA, 2000.

[12] M. Datta, Anodic dissolution of metals at high rates, IBM J. Res. Develop.37 (2) (1993) 207-226.

[13] M. Datta, R. V. Shenoy, L. T. Romankiw, "Recent advances in the study of electrochemical micromachining," ASME J. Eng. Ind. 118, 29-36, 1996.

[14] P.C. Pandey, H.S. e Shan, Modern Machining Processes, Tata McGraw Hill, New Delhi, 1980.

[15] G.F. Benedict, Nontraditional Manufacturing Processes- Electrochemical Machining, Marcel Dekker, New York and Basel, 1987, pp. 125-172. 